\title{
Application of Compost for Controlling Powdery Mildew of Pepper and its Effect on Productivity
}

\author{
Farag M.F. ${ }^{1}$; Taha, M.B. ${ }^{2}$; Kamel, S.M. $^{1}$ and \\ Mohamed, A.G. ${ }^{3}$
}

1- Plant Pathology Research Institute, ARC, Giza, Egypt.

2- Soils, Water and Environment Research Institute, ARC, Giza, Egypt.

3- Horticulture Research Institute, ARC, Giza, Egypt.

fficiency of compost (corn stover amended with sheep manure)
bioagents (Bacillus subtilis, Trichoderma harzianum and arbuscular
mycorrhizal fungi) was evaluated for suppressing powdery mildew of
pepper under field conditions. Experiments were carried out under natural
infection in the Experimental Farm of Sids Horticultural Research Station,
Agric. Res. Center, Beni-Sweif governorate. Two different methods of
application were used; soil amendment and or foliar spraying to reduce
pepper powdery mildew and improving its productivity, as well as
enhance soil fertility. All tested compost treatments reduced the number of
infected leaves and powdery mildew severity as well as increased the
yield compared to control treatment. On the other hand, spraying and
amendment pepper plants during the growing season with compost
combined with Trichoderma harzianum resulted in a significant decrease
in disease severity of the disease with significant increment in pepper
yield compared with the control treatment. In addition, combination the
compost with Bacillus subtilis gave the best results in controlling powdery
mildew of pepper.

Keywords: Biocides; compost; pepper; powdery mildew; Sulphur; gypsum.

Sweet pepper (Capsicum annuum L.) belongs to Solanaceae, and is considered one of the most essential, common and favorite vegetable crops cultivated in Egypt for local consumption and exportation. High cash crops such as sweet pepper have occupied an important rank in Egyptian and world agriculture due to its high profit and nutritional values for human health (Rajput and Poruleker, 1998). Like many other vegetable crops, pepper requires nutrition. For instance, each $100 \mathrm{~g}$ of green pepper contains $564 \mathrm{mg}$ potassium $(\mathrm{K}), 25-49 \mathrm{mg}$ phosphorus ( $\mathrm{P}, 10 \mathrm{mg}$ magnesium $(\mathrm{Mg}, 10-16 \mathrm{mg})$, Calcium (Ca and 0.7-1.4 mg, Ferrous (Fe) which are absorbed from soil (Csillery, 2006). Powdery mildew is a widespread leaf disease that affects several vegetable crops, in field and in greenhouse (Bourbos et al., 1999 and Matsuda et al., 2001). Pepper 
powdery mildew grows unseen, within the leaf tissue for a latency period of up to 21 days and the causative agent is Leveillula taurica.

Recently, highly attention has been focused on the possibility of using natural and safe bio-fertilizers for increasing growth and productivity of vegetable crops. Applying bio-fertilization to crops during plant growth stages promoting certain microorganisms and is currently considered as a healthy alternative to chemical fertilization. (Zhang et al., 2013).

Compost extract is a highly concentrated solution produced by extracting beneficial microbes through a liquid-phase of compost and its extraction period ranging from few hours to two weeks, with or without active aeration with the addition of some active nutrients, i.e., molasses, casein, etc. (Zaccardelli et al., 2012). Application of compost extracts is increasing due to their positive effects on the crops.

It can be used as foliar or soil organic nutrients, containing micronutrients for easy plant absorption. Such nutrients are biologically available for plant uptake. Compost extract is gaining importance as an alternative to chemical fertilizers and pesticides. The microbial population in the compost extract enhances its beneficial effectiveness on plant growth and considered as a valuable soil amendment (Gharib et al., 2008). These bio-fertilizers have the ability to mobilize plant nutrients in the soil from unusable to usable form. It is considered environmentally friendly, plays a significant role in crop production, helps to build up the micro flora and improve the soil fertility. Applications of alternative materials in suppressing foliar diseases in fields by using compost are limited. However, the available researches showed that composts suppress foliar diseases under field conditions, mainly by inducing plant defense systemic resistance (Zhang et al. 1996; Stone et al. 2003; Vallad et al. 2003).

Compost as an organic material influences agricultural sustainability by improving soil chemical, physical and biological properties as well as fertility by improving soil organic matter quality and soil structure and the moisture holding capacity (Rivero et al., 2004), supplies a wide range of beneficial microorganisms (Ryckeboer et al., 2003). However, the use of compost as soil amendments and their water extracts can provide natural biological control against foliar diseases (Zhang et al., 1996, 1998 and Stone et al., 2003) and improve plant health (Litterick et al., 2004).

Nutrients are essential for plant growth and development and they are important factors in disease control (Agrios, 2005) that may influence disease resistance or tolerance by increasing the capacity of the host plant to restrict invasive pathogens' penetration, development and reproduction (Dutta et al., 2017). Calcium is a major structural component of both cell walls and other plant membranes such as those surrounding organelles. A calcium deficiency results in tissues of plants that are less capable of actively fighting disease organism invasion is including downy and powdery mildew (Reuveni and Reuveni, 1998). Phosphorus, the second most commonly 
off-putting macronutrient for plant augmentation after nitrogen, which plays an important role in virtually all major metabolic processes in plants and pathogen (Khan et al., 2010). Phosphorus (P) is one of the major growth-limiting nutrients in plants, although it is abundant in soils as it is in an unavailable form for root uptake. In sustainable agriculture, the use of natural rock phosphate as a source of phosphorus and gypsum $\left(\mathrm{CaSO}_{4} \cdot 2 \mathrm{H}_{2} \mathrm{O}\right)$ as a calcium and sulphur fertilizer or as a soil conditioner at higher rates is more benefits than synthetic fertilizer.

Bio-control agents such as B. subtilis, T. harzianum and arbuscular mycorrhizal fungi (AM) have the ability to control powdery mildew (Kim et al., 2013), provide plants with growth promoting substances and play an important role in phosphate solubilizing and supplying P to plants (Tallapragada and Gudimi, 2011; Tanwar et al., 2013 and García-López and Delgado, 2016).

Therefore, the aim of this study was to assess the potential of compost modified with rock phosphate, gypsum and inoculated by certain bioagents (B. subtilis, T. harzianum and arbuscular mycorrhizal fungi) to control powdery mildew on pepper and to improve its productivity as well as soil fertility under field conditions using two methods of application: soil alteration and/or foliar spray

\section{Materials and Methods}

\section{Preparation of compost and compost extract:}

The organic waste material used in compost preparation from corn stover was cut into small pieces and taken to make the heaps (about 16 heaps each containing $50 \mathrm{Kg}$ stover). Farm yard manure (FYM) was added to each heap at the rate of $100 \mathrm{~kg} / \mathrm{ton}$. The materials of conditioners used and their application rates were gypsum (5\%) at the rate of $50 \mathrm{~kg} / \mathrm{ton}$, rock phosphate $(1 \%)$ at the rate of $10 \mathrm{~kg} / \mathrm{ton}$ and sulphur $(1 \%)$ at the rate of $10 \mathrm{~kg} / \mathrm{ton}$. The heaps were moistened with water and left up to the summer of each 2017 and 2018 growing season (four months). B. subtilis and Arbuscular Mycorrhizal fungi (mixed fungi belonging to genera Glomus, Gigaspora and Acaulospora) inocula used in this study were kindly obtained from Department of Microbiology, Soil, Water and Environment Res. Inst., ARC, Giza, Egypt while T. harzianum was isolated from the rhizosphere of pepper plants and identified in Assiut Univ., Mycological Center, Fac. of Sci., Assiut, Egypt (AUMC). Bacterial suspension was multiplied by cultivating B. subtilis in nutrient broth medium where $500 \mathrm{ml}$ conical flasks containing $200 \mathrm{ml}$ of the respective media were inoculated by one $\mathrm{ml}$ bacterial inocula of $24 \mathrm{~h}$ old culture and incubated in rotary shaking incubator $(120 \mathrm{rpm})$ at $28 \pm 2^{\circ} \mathrm{C}$ for $48 \mathrm{~h}$., Meanwhile, $T$. harzianum was grown in Trichoderma-selective medium broth (TSM) (Elad et al., 1981), amended with streptomycin and $50 \mu \mathrm{g} \mathrm{ml}^{-1}$ rose Bengal in conical flask, incubated at $25^{\circ} \mathrm{C}$ for 15 days. Trichoderma, Bacillus suspensions at the rate of $2 \mathrm{~L} /$ ton compost and $\mathrm{AM}$ fungi at the rate of $1 \mathrm{~kg} \mathrm{AM} /$ ton compost were added individually to the composting materials as a biodegradable agent a month after composting in order to accelerate the composting process. During composting process, water was monitored 
every week throughout the composting period to maintain it at $60 \%$.The 16 treatments were prepared by thoroughly mixing the corn stover with different additives. Treatments were arranged in piles according to the components of each pile and laid out in randomized block design, replicated three times and periodically were monitored during the process of composting until maturation.. For preparation of compost extract, $1 \mathrm{~kg}$ of mature compost from each treatment was mixed individually with $20 \mathrm{~L}$ of water in a container (ratio 1:20). The compost mixtures were homogenized and incubated in the laboratory for 7-8 days. Compost extracts were filtered through several layers of cheesecloth. The resultant compost extracts were applied as spray onto pepper leaves. Some characteristics of compost and compost extracts were performed

In vitro assay:

Effect of compost extract on conidial germination:

Drops of the tested compost extract were placed on glass slides and conidia of $L$. taurica were directly lifted with help of small paint brush from heavily infected pepper leaves. The slides were then placed in moist chambers prepared by placing two moist filter papers in the inner surfaces of a Petri plate. Conidia immersed in distilled water only as well as the fungicide Topas 100 EC suspension served as control. Three replications were made for each treatment. The slides were incubated at $25 \pm 2^{0} \mathrm{C}$ for $24 \mathrm{~h}$ and the percent of germination was calculated under a light microscope.

Field studies:

The trials were carried out under field conditions at Sids Horticultural Research Station, Agric. Res. Center, Beni-Sweif governorate in pepper fields through autumn seasons 2017 and 2018 to assess the potential of compost amended with sulphur, rock phosphate, gypsum and inoculated by some bioagents (B. subtilis, T. harzianum and AM fungi) to control powdery mildew on pepper and to improve its productivity as well as soil fertility using two application methods: soil amendment and/or foliar spray. Some physical and chemical characteristics of the used soil were determined before planting (Table, 1). The experiment was set in a randomized complete blocks design with two factors, three replications for each treatment. The first factor (main plot) assigned to the treatments tested and the second one (subplot, $3 \times 3.5 \mathrm{~m}$ ) to application methods.

During both experimental seasons, the following treatments were applied as soil amendment and/or foliar spray:
C1: Compost.
C2: Compost + Sulphur.
C3: Compost + Gypsum.
C4: Compost + Phosphate rock.
C5: Compost + AM fungi.
C6: Compost + B. subtilis.
C7: Compost + T. harzianum .
C8: Compost + Sulphur + AM fungi.
C9: Compost + Sulphur + B. subtilis.
C10: Compost + Sulphur + T. harzianum .
C11: Compost + Gypsum + AM fungi.
C12: Compost + Gypsum + B. subtilis .

Egypt. J. Phytopathol., Vol. 46, No. 2 (2018) 
C13: Compost. + Gypsum + T. harzianum .

C14: Compost. + Phosphate rock + AM fungi.

C15: Compost. + Phosphate rock + B. subtilis.

C16: Compost. + Phosphate rock + T. harzianum.

C17: The fungicide Topas $100 \mathrm{EC}$ at the rate of $25 \mathrm{~cm} 3 / 100 \mathrm{~L}$ water.

C18: Untreated control.

Table 1: The chemical and physical properties of the soil in experimental fields before planting.

\begin{tabular}{|c|l|l|}
\hline No. & Value & \multicolumn{1}{|c|}{ Soil characteristics } \\
\hline $\mathbf{1}$ & & Particle size distribution \\
\hline $\mathbf{2}$ & 4.25 & Coarse sand \\
\hline $\mathbf{3}$ & 9.31 & Fine sand \\
\hline $\mathbf{4}$ & 33.74 & Silt \\
\hline $\mathbf{5}$ & 52.70 & Clay \\
\hline $\mathbf{6}$ & Clayey & Textural class \\
\hline $\mathbf{7}$ & 16.32 & Exchangeable sodium percentage \\
\hline $\mathbf{8}$ & 41.59 & Field capacity \\
\hline $\mathbf{9}$ & 19.51 & Wilting point $\%$ \\
\hline $\mathbf{1 0}$ & 22.08 & Available water\% \\
\hline $\mathbf{1 1}$ & 8.60 & pH $(1-2.5$ soil- water suspension \\
\hline $\mathbf{1 2}$ & 1.45 & Calcium carbonate \% \\
\hline $\mathbf{1 3}$ & 1.08 & Organic carbon \% \\
\hline $\mathbf{1 4}$ & 1.868 & Organic matter \% \\
\hline $\mathbf{1 5}$ & 0.90 & Electric conductivity $(\mathrm{ds} / \mathrm{m})$ \\
\hline $\mathbf{1 6}$ & 16.35 & Cation exchange capacity $\mathrm{mg} / 100 \mathrm{~g}$ \\
\hline $\mathbf{1 7}$ & 0.089 & Total nitrogen \\
\hline $\mathbf{1 8}$ & 9.49 & Available $\mathrm{P}(\mathrm{mg} / \mathrm{kg}$ soil $)$ \\
\hline $\mathbf{1 9}$ & 239.81 & Available K $(\mathrm{mg} / \mathrm{kg}$ soil $)$ \\
\hline
\end{tabular}

Recommended field practices were undertaken $(\mathrm{N}, \mathrm{P}$ and $\mathrm{K}$ as recommended fertilizers). Pepper transplants (Balady cv.) were transplanted in autumn seasons 20172018 growing seasons. Application treatments were thoroughly mixed with the soil surface $(0-15 \mathrm{~cm})$ in the half of plants per plot otherwise, the second half of plants in each plot was not treated with compost but both halves of plants were carefully sprayed three times with compost extract onto pepper plants always performed early in the morning with the tested compost extracts. $1 \%$ Tween 20 was used before the appearance 
of first symptoms until run off. Monitoring and scouting the plants weekly for the appearance of powdery mildew and disease incidence and severity were estimated as follow.

Disease assessment:

Disease incidence:

Percentage of the disease incidence was recorded as the number of diseased plants relative to the number of growing plants for each row, then the average of disease incidence was calculated.

Disease severity:

Percentage of the disease severity was recorded as follow:

$$
\text { D.S. } \%=\frac{\Sigma(\mathrm{n} \times \mathrm{c})}{\mathrm{N} \times \mathrm{C}} \times 100
$$

Whereas: D.S. $=$ Disease severity $\%, \mathrm{n}=$ Number of infected leaves per category, $\mathrm{c}=$ Category number, $\mathrm{N}=$ Total examined leaves, $\mathrm{C}=$ The highest category number of infection

Disease severity scale from 0 to 4 according to Cohen et al., (1991) was followed, whereas: $0=$ No visible infection lesions; $1=25 \%$ or less; $2=26-50 \% ; 3=51-75$ $\%$ and $4=76-100 \%$ infected area of plant leaf.

Evaluation of pepper yield and its components:

At maturity, for each treatment, fruit yield and its components (fresh weight (ton/fed.), dry weight ( $\mathrm{kg} / \mathrm{fed}$.), final weight and fruit yield per plant $(\mathrm{kg})$ also, plant height $(\mathrm{cm})$, primary branches and plant numbers) were recorded. At the end of the growing season, the accumulated yield was calculated for each particular treatment.

Evaluation of vitamin $C$ :

Ascorbic acid (vitamin c mg/100 $\mathrm{g}$ fresh weight) was determined as 2,6 dichlorophenol indophenols dye according to (A.O.A.C, 1975)

Measurement of enzymatic activities:

Peroxidase activity was determined using the method described in the Worthington enzyme manual Worthington (1971) Polyphenoloxidase activity was measured following the method described by Esterbaner et al. (1977).

Statistical Analysis

Data were statistically analyzed for computing L.S.D. test at $5 \%$ probability according to the procedure outlined by Snedecor and Cochran (1989).

\section{Results}

Compost and compost extract analysis:

Data provided in Table 2, show the impact of composting treatments (sulpher, gypsum, phosphate rock and bioagents) on the compost and compost extract resultants. Overall, the addition of the tested conditioner and bioagents materials to compost 
increased electrical conductivity (EC), organic carbon (OC), content of organic material $(\mathrm{OM})$ and reduction of $\mathrm{pH}$ and $\mathrm{C} / \mathrm{N}$ ratio in compost, as well as increased NPK content in compost and compost extracts compared to the unamended plots with compost.

Table (2): Some characteristics of the resultant compost and compost extract as affected by the tested materials of conditioners and bioagents.

\begin{tabular}{|c|c|c|c|c|c|c|c|c|c|c|c|}
\hline \multirow{3}{*}{ 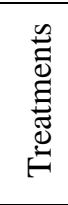 } & \multicolumn{11}{|c|}{ Mean of the two growing seasons } \\
\hline & \multicolumn{8}{|c|}{ Compost analysis } & \multicolumn{3}{|c|}{$\begin{array}{c}\text { Compost extracts } \\
\text { analysis }\end{array}$} \\
\hline & $\mathrm{OC} \%$ & $\begin{array}{c}\mathrm{OM} \\
\%\end{array}$ & $\mathrm{~N} \%$ & $\begin{array}{l}\mathrm{C} / \mathrm{N} \\
\text { ratio }\end{array}$ & $\mathrm{P} \%$ & $\mathrm{~K} \%$ & PH & $\mathrm{EC}$ & $\begin{array}{c}\mathrm{N}^{*} \\
\mathrm{ppm}\end{array}$ & $\begin{array}{c}\mathrm{P}^{*} \\
\mathrm{ppm}\end{array}$ & $\mathrm{K} * \%$ \\
\hline $\mathrm{C} 1$ & 30.62 & 52.79 & 1.46 & 20.97 & 0.341 & 1.707 & 8.26 & 12.65 & 1300 & 206.0 & 0.180 \\
\hline $\mathrm{C} 2$ & 33.41 & 57.61 & 1.55 & 21.55 & 0.368 & 1.815 & 7.12 & 13.85 & 1375 & 239.5 & 0.186 \\
\hline $\mathrm{C} 3$ & 32.11 & 55.36 & 1.60 & 20.07 & 0.448 & 2.026 & 8.12 & 11.45 & 1525 & 292.2 & 0.202 \\
\hline $\mathrm{C} 4$ & 33.05 & 56.98 & 1.63 & 20.28 & 0.394 & 1.920 & 7.93 & 11.03 & 1500 & 298.6 & 0.207 \\
\hline C5 & 31.00 & 54.83 & 1.49 & 21.54 & 0.349 & 1.786 & 8.22 & 12.37 & 1350 & 227.5 & 0.184 \\
\hline C6 & 32.37 & 55.81 & 1.51 & 21.44 & 0.365 & 1.755 & 8.19 & 11.92 & 1467 & 275.2 & 0.202 \\
\hline $\mathrm{C} 7$ & 31.99 & 55.16 & 1.50 & 21.33 & 0.350 & 1.739 & 8.18 & 11.97 & 1458 & 271.5 & 0.193 \\
\hline $\mathrm{C} 8$ & 34.19 & 58.94 & 1.55 & 22.06 & 0.374 & 1.842 & 7.11 & 13.74 & 1392 & 252.5 & 0.188 \\
\hline C9 & 35.30 & 60.86 & 1.55 & 22.77 & \begin{tabular}{|l}
0.383 \\
\end{tabular} & 1.868 & 7.14 & 13.40 & 1433 & 263.3 & 0.190 \\
\hline $\mathrm{C} 10$ & 34.65 & 59.74 & 1.54 & 22.22 & 0.365 & 1.840 & 7.18 & 13.44 & 1425 & 263.3 & 0.189 \\
\hline $\mathrm{C} 11$ & 33.27 & 57.36 & 1.61 & 20.71 & 0.445 & 2.040 & 8.03 & 11.18 & 1525 & 304.2 & 0.208 \\
\hline $\mathrm{C} 12$ & 33.62 & 57.97 & 1.63 & 20.63 & 0.459 & 2.060 & 8.01 & 11.19 & 1567 & 315.3 & 0.211 \\
\hline $\mathrm{C} 13$ & 33.64 & 58.35 & 1.61 & 21.44 & 0.460 & 2.000 & 8.07 & 11.31 & 1550 & 306.5 & 0.211 \\
\hline C14 & 34.73 & 59.88 & 1.65 & \begin{tabular}{|l|}
21.10 \\
\end{tabular} & \begin{tabular}{|l}
0.403 \\
\end{tabular} & 1.935 & 7.86 & 10.64 & 1550 & 337.5 & 0.209 \\
\hline C15 & 36.23 & 62.46 & 1.64 & 22.10 & 0.409 & 1.966 & 7.78 & 10.65 & 1300 & 206.0 & 0.180 \\
\hline C16 & 35.08 & 60.48 & 1.61 & 21.74 & 0.400 & 1.959 & 7.83 & 10.83 & 1375 & 239.5 & 0.186 \\
\hline
\end{tabular}

*Soluble NPK in compost extract.

Effect of compost extract on conidial germination:

Results presented in Table, 3 show that all treatments significantly reduced spore germination of $L$. taurica. The highest reduction was observed with treatment of fungicide Topas $100 \mathrm{EC}\left(\mathrm{C}_{17}\right)$ followed by compost + phosphate rock + B. subtilis treatment $\left(\mathrm{C}_{15}\right)$ with significant differences between them, being 89.3 and $82.1 \%$, respectively followed by compost + phosphate rock $+T$. harzianum treatment $\left(\mathrm{C}_{16}\right)$ and compost + gypsum $+B$. subtilis $\left(\mathrm{C}_{12}\right)$, without significant differences between them being 78.6\%. Moreover, moderate reduction was observed with the treatments of Compost. + Gypsum + T. harzianum $\left(\mathrm{C}_{13}\right)$, Compost + B. subtilis. $\left(\mathrm{C}_{6}\right)$, Compost. + Phosphate rock + AM fungi $\left(\mathrm{C}_{14}\right)$ and Compost $+T$. harzianum $\left(\mathrm{C}_{7}\right)$, being 75.0, 75.0,

Egypt. J. Phytopathol., Vol. 46, No. 2 (2018) 
71.4 and $71.4 \%$, respectively. The use of compost only $\left(\mathrm{C}_{1}\right)$ and compost + sulphur $\left(\mathrm{C}_{2}\right)$ showed the lowest inhibition in spore germination, being $50 \%$ without significant differences between them followed by treatments of compost $+\mathrm{AM}$ fungi $\left(\mathrm{C}_{5}\right)$ and compost + sulphur + AM fungi $\left(\mathrm{C}_{8}\right)$ without significant differences between them being $57.1 \%$.

Table (3): Effect of components of compost extract on spore germination of Leveillula taurica.

\begin{tabular}{|c|c|c|}
\hline Treatments & Spore germination $\%$ & Reduction ${ }^{*} \%$ \\
\hline C1 & 14 & 50.0 \\
\hline C2 3 & 14 & 50.0 \\
\hline C4 & 11 & 60.7 \\
\hline C5 & 9 & 67.9 \\
\hline C6 & 12 & 57.1 \\
\hline C7 8 & 7 & 75.0 \\
\hline C9 10 & 8 & 71.4 \\
\hline C11 & 12 & 57.1 \\
\hline C12 & 11 & 60.7 \\
\hline C13 & 10 & 64.3 \\
\hline C14 & 10 & 64.3 \\
\hline C15 & 6 & 78.6 \\
\hline C16 & 7 & 75.0 \\
\hline C17 & 8 & 71.4 \\
\hline C18 & 5 & 82.1 \\
\hline LSD at 0.05 & 6 & 78.6 \\
\hline & 3 & 89.3 \\
\hline
\end{tabular}

Effect of compost and compost extract on disease incidence and severity:

Data presented in Table, 4, and Figs. 1 and 2 illustrate that there were significant differences among treatments in their effect on powdery mildew incidence and severity. In general, addition of phosphate rock and gypsum with bioagents to compost improved its efficiency than each one alone. Among all treatments, the fungicide Topas 100 EC $\left(\mathrm{C}_{17}\right)$ was the most efficient in this regard which recorded the lowest disease incidence, being $6.9 \%$, followed by compost + phosphate rock + B. subtilis treatment $\left(\mathrm{C}_{15}\right)$ and compost + phosphate rock $+T$. harzianum treatment $\left(\mathrm{C}_{16}\right)$. The corresponding mean values in disease incidence were 6.9 and $7.1 \%$ and disease severity, being 5.7 and 5.8 $\%$, respectively on the average of two seasons 2017 and 2018 .Application of compost + gypsum $+B$. subtilis $\left(\mathrm{C}_{12}\right)$ showed moderate efficiency in reducing disease incidence and severity followed by compost + gypsum $+T$. harzianum $\left(\mathrm{C}_{13}\right)$. On the other hand, addition of bioagents to compost increased their efficiency in reducing the disease

Egypt. J. Phytopathol., Vol. 46, No. 2 (2018) 
incidence and severity than addition of phosphate rock or gypsum to compost. In this regard, treatment of compost $+B$. subtilis $\left(\mathrm{C}_{6}\right)$ was more efficient followed by compost $+T$. harzianum $\left(\mathrm{C}_{7}\right)$. Application of compost alone or supplemented with sulphur or with mycorrhizae gave the lowest efficiency. Generally, the effectiveness of the tested treatments significantly varied according to the application method. Soil amendment with the tested treatments and spraying the leaves with compost extract was the most effective in reducing the disease incidence and severity than spraying the foliar by compost extract only.

Table (4): Effect of different compost treatments and two different methods of application on the incidence and severity of powdery mildew on pepper plants.

\begin{tabular}{|c|c|c|c|c|c|c|c|c|c|}
\hline \multirow{4}{*}{ 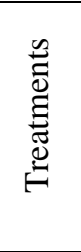 } & \multicolumn{9}{|c|}{ Mean of the two growing seasons } \\
\hline & \multicolumn{9}{|c|}{ Application methods (M) } \\
\hline & \multicolumn{3}{|c|}{ Disease incidence \% } & \multicolumn{3}{|c|}{ Disease severity $\%$} & \multicolumn{3}{|c|}{ AUDPC } \\
\hline & $\begin{array}{l}\text { Foliar } \\
\text { spray }\end{array}$ & $\begin{array}{c}\text { Soil } \\
\text { amend. + } \\
\text { Foliar } \\
\text { spray }\end{array}$ & Mean (T) & $\begin{array}{l}\text { Foliar } \\
\text { spray }\end{array}$ & $\begin{array}{c}\text { Soil } \\
\text { amend. }+ \\
\text { Foliar } \\
\text { spray } \\
\end{array}$ & Mean $(\mathrm{T})$ & $\begin{array}{l}\text { Foliar } \\
\text { spray }\end{array}$ & \begin{tabular}{|c|} 
Soil \\
amend. + \\
Foliar \\
spray \\
\end{tabular} & Mean (T) \\
\hline $\mathrm{C} 1$ & 14.5 & 12.2 & 13.4 & 11.3 & 7.6 & 9.5 & 424.0 & 289.0 & 356.5 \\
\hline $\mathrm{C} 2$ & 14.3 & 11.1 & 12.7 & 10.1 & 7.6 & 8.9 & 255.15 & 226.5 & 240.9 \\
\hline $\mathrm{C} 3$ & 13.4 & 10.9 & 12.2 & 9.4 & 7.1 & 8.3 & 267.1 & 298.0 & 282.6 \\
\hline $\mathrm{C} 4$ & 11.8 & 9.9 & 10.9 & 8.9 & 6.6 & 7.8 & 272.3 & 260.0 & 266.2 \\
\hline $\mathrm{C} 5$ & 13.7 & 11.1 & 12.4 & 10.1 & 7.5 & 8.8 & 289.8 & 345.5 & 317.7 \\
\hline C6 & 10.2 & 8.6 & 9.4 & 8.1 & 6.3 & 7.2 & 256.9 & 282.0 & 269.5 \\
\hline C7 & 11.7 & 8.8 & 10.3 & 8.2 & 6.3 & 7.3 & 175.7 & 337.0 & 256.4 \\
\hline $\mathrm{C} 8$ & 13.4 & 11.0 & 12.2 & 9.8 & 7.5 & 8.7 & 407.5 & 301.5 & 254.5 \\
\hline C9 & 13.4 & 10.9 & 12.2 & 9.6 & 7.3 & 8.5 & 271.6 & 309.0 & 290.3 \\
\hline $\mathrm{C} 10$ & 12.5 & 10.3 & 11.4 & 9.4 & 7.1 & 8.3 & 558.8 & 268.0 & 413.4 \\
\hline C11 & 12.4 & 10.3 & 11.4 & 9.2 & 7.0 & 8.1 & \begin{tabular}{|l|l}
337.5 \\
\end{tabular} & 251.5 & 294.5 \\
\hline C12 & 10.1 & 7.6 & 8.9 & 7.2 & 4.7 & 6.0 & 252.0 & 281.5 & 266.8 \\
\hline C13 & 10.2 & 7.9 & 9.1 & 8.1 & 5.9 & 7.0 & 256.6 & 313.0 & 284.8 \\
\hline C14 & 11.8 & 9.5 & 10.7 & 8.4 & 6.4 & 7.4 & 257.3 & 285.0 & 271.2 \\
\hline C15 & 9.5 & 6.9 & 8.2 & 6.8 & 4.5 & 5.7 & 292.9 & 298.5 & 295.7 \\
\hline $\mathrm{C} 16$ & 9.7 & 7.1 & 8.4 & 7.1 & 4.5 & 5.8 & 273.7 & 318.0 & 295.9 \\
\hline C17 & 7.8 & 5.9 & 6.9 & 5.6 & 3.9 & 4.8 & 225.4 & 250.0 & 237.7 \\
\hline $\mathrm{C} 18$ & 66.4 & 57.2 & 61.8 & 66.4 & 57.2 & 61.8 & 861.5 & 882.5 & 872.0 \\
\hline $\begin{array}{l}\text { Mean } \\
\text { (M) }\end{array}$ & 14.8 & 12.1 & --- & 11.9 & 9.2 & --- & 329.8 & 322.0 & --- \\
\hline $\begin{array}{l}\text { LSD } \\
\text { at } 0.05\end{array}$ & \multicolumn{3}{|c|}{$\mathrm{T}=0.7 \mathrm{M}=0.2 \mathrm{TM}=1.0$} & \multicolumn{3}{|c|}{$\mathrm{T}=0.9 \mathrm{M}=0.3 \mathrm{TM}=1.2$} & \multicolumn{3}{|c|}{$\mathrm{T}=15.7 \mathrm{M}=5.2 \mathrm{TM}=22.2$} \\
\hline
\end{tabular}

Egypt. J. Phytopathol., Vol. 46, No. 2 (2018) 


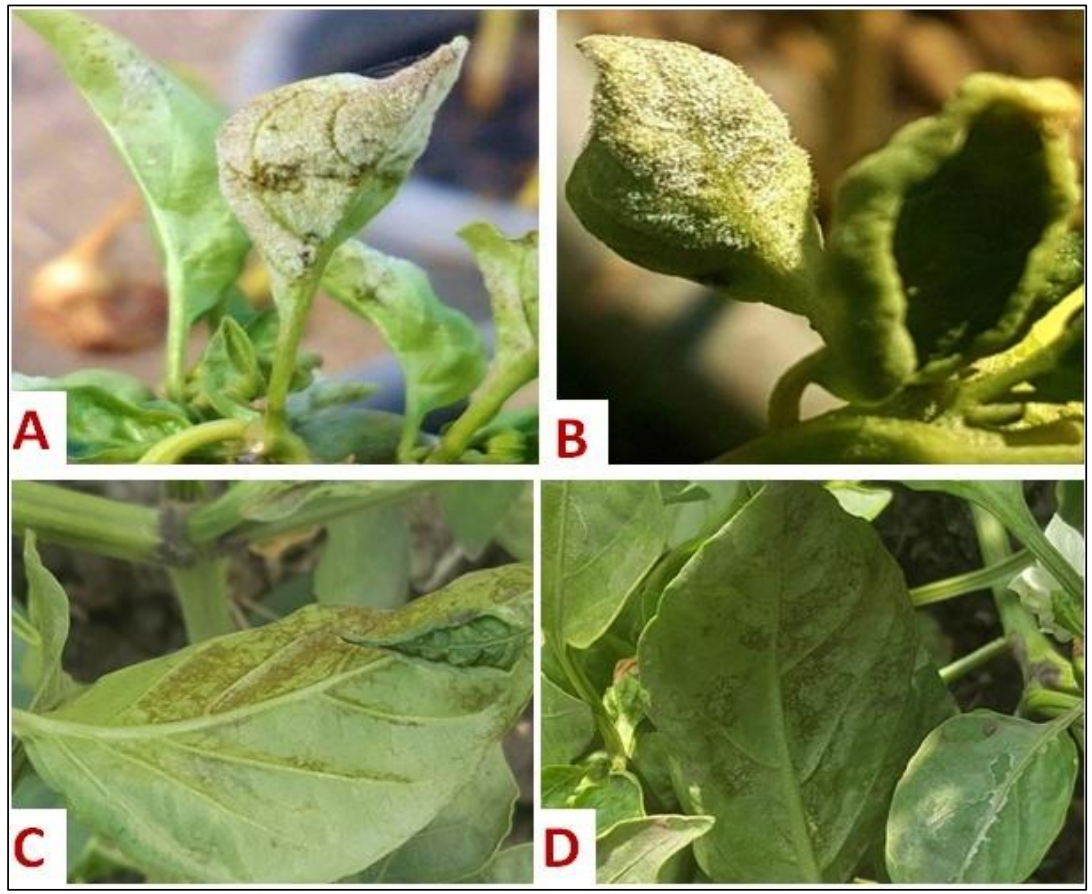

Fig. (1): Effect of compost supplemented with bioagents on pepper powdery mildew C, D compared with control A, B foliage

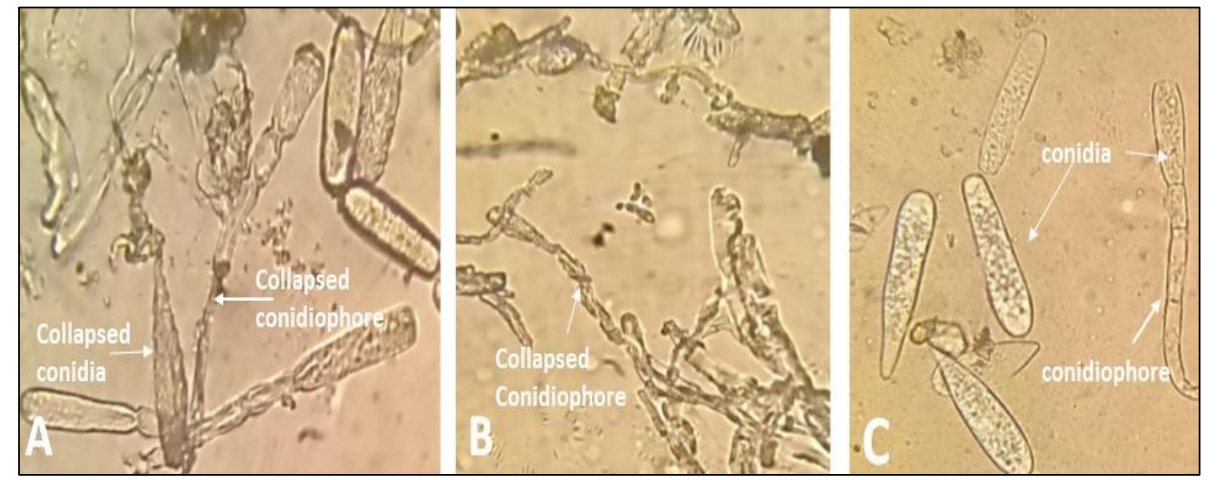

Fig. (2): A- Effect of compost mixed with Trichoderma spray; B- Effect of compost mixed with Bacillus subtilis spray; C- control, (400X)

Egypt. J. Phytopathol., Vol. 46, No. 2 (2018) 
Evaluation of pepper yield and its components and NPK uptake:

In fact, addition of compost, alone or combined with sulphur, rock phosphate, gypsum and different tested bioagents promoted the growth of pepper plants and significantly increased the plant height, number of branches, fruit weight, fruit yield per plant and vitamins in both seasons compared to the untreated plants (Tables, 5 and 6).

Table (5): Effect of interaction between compost extract, supplemented with bioagents, sulphur, phosphate rock and gypsum on plant height and Number / branches plant Number during the two successive growing seasons.

\begin{tabular}{|c|c|c|c|c|c|c|}
\hline \multirow{4}{*}{ 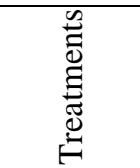 } & \multicolumn{6}{|c|}{ Mean of the two growing seasons } \\
\hline & \multicolumn{6}{|c|}{ Application methods (M) } \\
\hline & \multicolumn{3}{|c|}{ Plant height $(\mathrm{cm})$} & \multicolumn{3}{|c|}{ Primary branches / plant (No) } \\
\hline & spray & A.*+ spray & Mean $(\mathrm{T})$ & spray & A.+ spray & Mean $(T)$ \\
\hline $\mathrm{C} 1$ & 54.50 & 55.65 & 55.08 & 3.00 & 3.30 & 3.15 \\
\hline $\mathrm{C} 2$ & 55.70 & 57.19 & 56.45 & 3.10 & 3.50 & 3.30 \\
\hline $\mathrm{C} 3$ & 57.70 & 60.88 & 59.29 & 3.20 & 4.00 & 3.60 \\
\hline $\mathrm{C} 4$ & 58.33 & 61.35 & 59.84 & 3.50 & 4.10 & 3.80 \\
\hline $\mathrm{C} 5$ & 55.00 & 56.55 & 55.78 & 3.10 & 3.50 & 3.30 \\
\hline C6 & 56.33 & 59.56 & 57.95 & 3.20 & 3.80 & 3.50 \\
\hline $\mathrm{C} 7$ & 56.65 & 59.49 & 58.07 & 3.20 & 3.70 & 3.45 \\
\hline $\mathrm{C} 8$ & 56.60 & 57.57 & 57.09 & 3.15 & 3.70 & 3.43 \\
\hline C9 & 57.60 & 60.31 & 58.96 & 3.25 & 3.90 & 3.58 \\
\hline $\mathrm{C} 10$ & 57.50 & 57.59 & 57.55 & 4.25 & 3.80 & 4.03 \\
\hline C11 & 58.60 & 62.33 & 60.47 & 3.30 & 4.00 & 3.65 \\
\hline $\mathrm{C} 12$ & 60.60 & 65.77 & 63.19 & 3.50 & 4.50 & 4.00 \\
\hline $\mathrm{C} 13$ & 60.00 & 63.42 & 61.71 & 3.35 & 4.20 & 3.78 \\
\hline C14 & 60.40 & 62.95 & 61.68 & 3.35 & 4.25 & 3.80 \\
\hline C15 & 61.10 & 66.13 & 63.89 & 3.60 & 4.60 & 4.10 \\
\hline C16 & 60.75 & 64.95 & 62.85 & 3.50 & 4.40 & 3.95 \\
\hline C17 & 54.50 & 56.50 & 55.50 & 3.30 & 3.50 & 3.85 \\
\hline C18 & 52.60 & 52.85 & 52.73 & 2.80 & 3.00 & 2.90 \\
\hline Mean M & 57.47 & 60.06 & --- & 3.31 & 3.88 & --- \\
\hline LSD 0.05 & 6.698 & 3.091 & & 0.476 & 0.324 & \\
\hline
\end{tabular}

*soil amendment

The highest values were recorded due to using $\mathrm{C}_{15}$ (treatment of compost combined with phosphate rock and inoculated with $B$. subtilis) followed by $\mathrm{C}_{16}$ (compost + phosphate rock $+T$. harzianum treatment) with significant differences between them. The corresponding mean values were $61.10 \& 66.13 \mathrm{~cm}$, for plant height; $3.60 \& 4.60$, 
for branches number/plant $19.20 \& 21.50 \mathrm{gm}$ for fruit weight $0.92 /$ plant and, $97.02 \&$ 93.50 on the average, respectively. For vitamin C. Compost + gypsum + B. subtilis (C12) gave moderate values in this respect followed by compost + gypsum $+T$. harzianum $\left(\mathrm{C}_{11}\right)$ and Compost + gypsium $+\mathrm{AM}$ fungi treatment $\left(\mathrm{C}_{10}\right)$. Meanwhile, addition of compost only without any amendments $\left(\mathrm{C}_{1}\right)$ gave the lowest plant height $(55.08 \mathrm{~cm})$, branches no./plant (3.15), fruit weight $(18.25)$, Fruit yield / plant $(0.80 \mathrm{gm})$ and vitamin C (91.10). Generally, soil amendment with the tested compost treatments and spraying the foliar with compost extract caused a significant promotion to plant growth than spraying the foliar with compost extract only.

Table (6): Effect of interaction between compost extract, supplemented with bioagents, sulphur, phosphate rock and gypsum on fruit weight, fruit yield/plant and vitamin $\mathrm{C}$ during the two successive growing seasons.

\begin{tabular}{|c|c|c|c|c|c|c|c|c|c|}
\hline \multirow{4}{*}{ 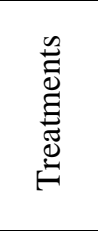 } & \multicolumn{9}{|c|}{ Mean of the two growing seasons } \\
\hline & \multicolumn{9}{|c|}{ Application methods (M) } \\
\hline & \multicolumn{3}{|c|}{ Fruit weight gm } & \multicolumn{3}{|c|}{ Fruit yield/plant (kg) } & \multicolumn{3}{|c|}{ Vitamin $\mathrm{C}$} \\
\hline & spray & $\begin{array}{c}\text { A.+ } \\
\text { spray }\end{array}$ & $\begin{array}{l}\text { Mean } \\
(\mathrm{T})\end{array}$ & spray & $\begin{array}{c}\text { A.+ } \\
\text { spray }\end{array}$ & $\begin{array}{l}\text { Mean } \\
(\mathrm{T})\end{array}$ & spray & $\begin{array}{l}\text { A.+ } \\
\text { spray }\end{array}$ & $\begin{array}{l}\text { Mean } \\
(\mathrm{T})\end{array}$ \\
\hline $\mathrm{C} 1$ & 18.00 & 18.50 & 18.25 & 0.76 & 0.83 & 0.80 & 90.30 & 91.89 & 91.10 \\
\hline $\mathrm{C} 2$ & 18.20 & 18.80 & 18.50 & 0.77 & 0.85 & 0.81 & 91.50 & 93.71 & 92.61 \\
\hline $\mathrm{C} 3$ & 18.50 & 19.50 & 19.00 & 0.80 & 090 & 0.85 & 92.80 & 94.19 & 93.50 \\
\hline $\mathrm{C} 4$ & 18.50 & 20.00 & 19.25 & 0.8 & 0.92 & 0.87 & 93.05 & 95.62 & 94.34 \\
\hline $\mathrm{C} 5$ & 18.25 & 18.70 & 18.48 & 0.77 & 0.85 & 0.81 & 91.60 & 93.50 & 92.55 \\
\hline C6 & 18.30 & 19.00 & 18.65 & 0.79 & 0.90 & 0.85 & 92.00 & 94.85 & 93.43 \\
\hline $\mathrm{C} 7$ & 18.30 & 19.00 & 18.65 & 0.78 & 0.88 & 0.83 & 91.80 & 94.06 & 92.93 \\
\hline $\mathrm{C} 8$ & 18.20 & 18.90 & 18.55 & 0.78 & 0.87 & 0.83 & 91.68 & 94.65 & 93.17 \\
\hline C9 & 18.40 & 19.20 & 18.80 & 0.80 & 0.88 & 0.84 & 92.43 & 95.93 & 94.18 \\
\hline $\mathrm{C} 10$ & 18.30 & 19.00 & 18.65 & 0.80 & 0.87 & 0.84 & 92.00 & 94.46 & 93.23 \\
\hline C11 & 18.75 & 20.20 & 19.48 & 0.82 & 0.93 & 0.88 & 93.00 & 95.77 & 94.39 \\
\hline $\mathrm{C} 12$ & 19.00 & 20.50 & 19.75 & 0.85 & 0.95 & 0.90 & 93.25 & 96.87 & 95.06 \\
\hline $\mathrm{C} 13$ & 18.80 & 20.20 & 19.50 & 0.83 & 0.94 & 0.89 & 93.10 & 96.05 & 94.58 \\
\hline $\mathrm{C} 14$ & 18.80 & 20.75 & 23.78 & 0.85 & 0.94 & 0.90 & 93.20 & 95.80 & 94.50 \\
\hline $\mathrm{C} 15$ & 19.20 & 21.50 & 20.35 & 0.85 & 098 & 0.92 & 93.50 & 97.02 & 95.26 \\
\hline C16 & 19.00 & 21.00 & 20.00 & 0.87 & 0.97 & 0.92 & 93.35 & 96.95 & 95.15 \\
\hline C17 & 18.50 & 18.50 & 18.50 & 0.85 & 0.85 & 0.85 & 92.35 & 92.35 & 92.35 \\
\hline C18 & 17.00 & 16.50 & 16.75 & 0.75 & 0.65 & 0.70 & 90.10 & 88.10 & 89.10 \\
\hline $\begin{array}{l}\text { Mean } \\
(\mathrm{M})\end{array}$ & 18.44 & 19.43 & -- & 0.8 & 0.89 & --- & 92 & 94.54 & --- \\
\hline $\begin{array}{l}\text { LSD } \\
\text { at } 0.05\end{array}$ & \multicolumn{3}{|c|}{$\begin{array}{c}\mathrm{T}=1.15 \mathrm{M}=0.38 \\
\mathrm{TM}=1.63\end{array}$} & \multicolumn{3}{|c|}{$\begin{array}{c}\mathrm{T}=0.03 \quad \mathrm{M}=0.01 \\
\mathrm{TM}=0.05\end{array}$} & \multicolumn{3}{|c|}{$\begin{array}{c}\mathrm{T}=2.34 \mathrm{M}=0.78 \\
\mathrm{TM}=3.31\end{array}$} \\
\hline
\end{tabular}

Egypt. J. Phytopathol., Vol. 46, No. 2 (2018) 
The present results (Tables, 7 and 8 ) indicate that fresh \& dry fruits, yield ( $\mathrm{kg} / \mathrm{fed}$.) were significantly affected by the application of various compost treatments. The highest plant fresh weight, being 8.35 and 8.30 ton/fed., dry weight (577.27 and 574.07 $\mathrm{kg} / \mathrm{fed}$.), respectively for the fruits yield were obtained from $\mathrm{C}_{15}$ (treatment of compost + phosphate rock $+B$. subtilis) followed by $\mathrm{C}_{16}$ (compost + phosphate rock $+T$. harzianum). However the treatments of compost + gypsum $+B$. subtilis $\left(\mathrm{C}_{12}\right)$, compost + gypsum $+T$. harzianum $\left(\mathrm{C}_{13}\right)$ and compost + phosphate rock $+\mathrm{AM}$ fungi $\left(\mathrm{C}_{14}\right)$ showed moderate fresh and dry weights of fruits yield with significant differences among them. While application of compost only without any addition gave the lowest fresh and dry weights of fruits yield compared to the other treatments. The corresponding mean values of fresh weight were $7.10,8.13$ ton/fed and dry weight, being 496.77 , and $573.97 \mathrm{~kg} / \mathrm{fed}$, respectively for fruits yield. On the other hand application of various compost treatments as soil amendments and spraying the pepper foliage by compost extract significantly increased the fresh and dry weights of fruits yield than spraying the pepper foliage by compost extract only.

Table (7): Effect of compost amended with sulphur, phosphate, gypsum and bioagents on fresh and dry weigh.

\begin{tabular}{|c|c|c|c|c|c|c|}
\hline \multirow{4}{*}{ 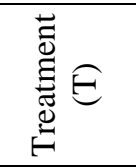 } & \multicolumn{6}{|c|}{ Mean of the two growing seasons } \\
\hline & \multicolumn{6}{|c|}{ Application methods } \\
\hline & \multicolumn{3}{|c|}{ Fresh weight (ton/fed.) } & \multicolumn{3}{|c|}{ Dry weight (kg/fed.) } \\
\hline & spray & A.+ spray & Mean $(\mathrm{T})$ & spray & A.+ spray & Mean $(\mathrm{T})$ \\
\hline $\mathrm{C} 1$ & 7.10 & 8.13 & 7.62 & 496.77 & 573.97 & 530.37 \\
\hline $\mathrm{C} 2$ & 7.20 & 8.37 & 7.79 & 505.13 & 588.93 & 547.03 \\
\hline $\mathrm{C} 3$ & 7.47 & 8.57 & 8.02 & 513.77 & 599.07 & 556.42 \\
\hline $\mathrm{C} 4$ & 7.40 & 8.57 & 7.99 & 514.07 & 608.13 & 561.10 \\
\hline $\mathrm{C} 5$ & 7.27 & 8.40 & 7.84 & 507.67 & 588.07 & 547.87 \\
\hline C6 & 7.47 & 8.53 & 8.00 & 512.43 & 594.70 & 553.57 \\
\hline $\mathrm{C} 7$ & 7.40 & 8.50 & 7.95 & 511.33 & 593.60 & 552.47 \\
\hline $\mathrm{C} 8$ & 7.30 & 8.40 & 7.85 & 510.37 & 589.67 & 550.02 \\
\hline C9 & 7.33 & 8.43 & 7.88 & 510.47 & 592.13 & 551.30 \\
\hline $\mathrm{C} 10$ & 7.33 & 8.40 & 7.87 & 508.30 & 590.80 & 549.55 \\
\hline $\mathrm{C} 11$ & 7.50 & 8.63 & 8.07 & 515.43 & 608.83 & 562.13 \\
\hline $\mathrm{C} 12$ & 7.70 & 8.77 & 8.24 & 519.23 & 622.50 & 570.87 \\
\hline $\mathrm{C} 13$ & 7.63 & 8.77 & 8.20 & 518.23 & 619.67 & 568.95 \\
\hline $\mathrm{C} 14$ & 7.60 & 8.67 & 8.14 & 516.60 & 611.13 & 563.87 \\
\hline $\mathrm{C} 15$ & 7.80 & 8.90 & 8.35 & 522.60 & 631.93 & 577.27 \\
\hline $\mathrm{C} 16$ & 7.77 & 8.83 & 8.30 & 520.47 & 627.67 & 574.07 \\
\hline $\mathrm{C} 17$ & 7.27 & 8.30 & 7.79 & 500.97 & 582.73 & 541.85 \\
\hline $\mathrm{C} 18$ & 6.20 & 6.23 & 6.22 & 445.33 & 434.43 & 439.88 \\
\hline Mean (M) & 7.37 & 8.41 & --- & 508.29 & 592.11 & --- \\
\hline LSD 0.05 & \multicolumn{3}{|c|}{$\mathrm{T}=0.58 \mathrm{M}=0.19 \mathrm{TM}=0.82$} & \multicolumn{3}{|c|}{$\mathrm{T}=19.18 \mathrm{M}=6.39 \mathrm{TM}=27.12$} \\
\hline
\end{tabular}


Table (8): Effect of compost amended with sulphur, phosphate, gypsum and bioagents on NPK uptake.

\begin{tabular}{|c|c|c|c|c|c|c|c|c|c|}
\hline \multirow{4}{*}{ 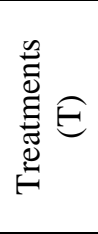 } & \multicolumn{9}{|c|}{ Mean of the two growing seasons } \\
\hline & \multicolumn{9}{|c|}{ Application methods (M) } \\
\hline & \multicolumn{3}{|c|}{ N Uptake (kg/fed.) } & \multicolumn{3}{|c|}{ P Uptake (kg/fed.) } & \multicolumn{3}{|c|}{ K Uptake (kg/fed.) } \\
\hline & spray & $\begin{array}{c}\text { A.+ } \\
\text { spray }\end{array}$ & $\begin{array}{c}\text { Mean } \\
(\mathrm{T})\end{array}$ & spray & $\begin{array}{c}\text { A.+ } \\
\text { spray }\end{array}$ & $\begin{array}{l}\text { Mean } \\
(\mathrm{T})\end{array}$ & spray & $\begin{array}{c}\text { A.+ } \\
\text { Spray }\end{array}$ & $\begin{array}{l}\text { Mean } \\
(\mathrm{T}) \\
\end{array}$ \\
\hline $\mathrm{C} 1$ & 5.87 & 7.03 & 6.45 & 1.00 & 1.17 & 1.09 & 4.79 & 5.10 & 4.95 \\
\hline $\mathrm{C} 2$ & 6.33 & 7.53 & 6.93 & 1.07 & 1.23 & 1.15 & 5.00 & 5.40 & 5.20 \\
\hline $\mathrm{C} 3$ & 6.63 & 7.93 & 7.28 & 1.13 & 1.33 & 1.23 & 5.25 & 5.73 & 5.49 \\
\hline $\mathrm{C} 4$ & 6.53 & 7.93 & 7.23 & 1.13 & 1.40 & 1.27 & 5.28 & 5.63 & $5.46+$ \\
\hline $\mathrm{C} 5$ & 6.30 & 7.53 & 6.92 & 1.03 & 1.23 & 1.13 & 5.02 & 5.40 & 5.21 \\
\hline C6 & 6.47 & 7.93 & 7.20 & 1.10 & 1.30 & 1.20 & 5.15 & 5.57 & 5.36 \\
\hline $\mathrm{C} 7$ & 6.47 & 7.80 & 7.14 & 1.10 & 1.30 & 1.20 & 5.12 & 5.57 & 5.35 \\
\hline $\mathrm{C} 8$ & 6.37 & 7.63 & 7.00 & 1.07 & 1.27 & 1.17 & 5.14 & 5.53 & 5.34 \\
\hline C9 & 6.43 & 7.70 & 7.07 & 1.07 & 1.27 & 1.17 & 5.20 & 5.57 & 5.39 \\
\hline $\mathrm{C} 10$ & 6.43 & 7.63 & 7.03 & 1.07 & 1.27 & 1.17 & 5.17 & 5.53 & 5.35 \\
\hline $\mathrm{C} 11$ & 6.80 & 7.93 & 7.37 & 1.21 & 1.35 & 1.28 & 5.34 & 5.73 & 5.54 \\
\hline $\mathrm{C} 12$ & 7.07 & 8.63 & 7.85 & 1.27 & 1.47 & 1.37 & 5.32 & 5.80 & 5.56 \\
\hline $\mathrm{C} 13$ & 7.00 & 8.13 & 7.57 & 1.23 & 1.43 & 1.33 & 5.42 & 5.80 & 5.61 \\
\hline $\mathrm{C} 14$ & 6.80 & 8.03 & 7.42 & 1.23 & 1.40 & 1.32 & 5.30 & 5.73 & 5.52 \\
\hline $\mathrm{C} 15$ & 7.07 & 8.93 & 8.00 & 1.40 & 1.50 & 1.45 & 5.39 & 5.87 & 5.63 \\
\hline $\mathrm{C} 16$ & 7.07 & 8.80 & 7.94 & 1.27 & 1.50 & 1.39 & 5.39 & 5.87 & 5.63 \\
\hline $\mathrm{C} 17$ & 6.25 & 7.07 & 6.66 & 1.10 & 1.25 & 1.18 & 4.49 & 5.10 & 4.80 \\
\hline $\mathrm{C} 18$ & 5.13 & 5.17 & 5.15 & 0.83 & 0.87 & 0.85 & 3.92 & 5.40 & 4.66 \\
\hline $\begin{array}{c}\text { Mean } \\
(\mathrm{M})\end{array}$ & 6.50 & 7.74 & -- & 1.13 & 1.31 & --- & 5.09 & 5.57 & --- \\
\hline $\begin{array}{l}\text { LSD } \\
\text { at } 0.05\end{array}$ & \multicolumn{3}{|c|}{$\begin{array}{c}\mathrm{T}=0.64 \mathrm{M}=0.21 \mathrm{TM} \\
=0.90\end{array}$} & \multicolumn{3}{|c|}{$\begin{array}{c}\mathrm{T}=0.05 \mathrm{M}=0.01 \mathrm{TM} \\
=0.06\end{array}$} & \multicolumn{3}{|c|}{$\begin{array}{c}\mathrm{T}=0.43 \mathrm{M}=0.14 \mathrm{TM} \\
=0.60\end{array}$} \\
\hline
\end{tabular}

*soil amendment

\section{Effect of compost on physical and chemical characteristics of soil}

Data presented in Table (9) illustrate the effect of different compost treatments tested on some physical and chemical characteristics of soil at the end of the growing season. Generally, all different compost treatments either alone or in combination with bioagents, sulphur, phosphate rock and gypsum caused decrease in soil $\mathrm{pH}$ values as compared with control value. Soil $\mathrm{pH}$ value of 8.57 was recorded in the control whilst; minimum $\mathrm{pH}$ value (8.35) was recorded in $\mathrm{C}_{15}$ (compost + phosphate rock $+T$. harzianum treatment) followed by, $\mathrm{C}_{16}$ (treatment of compost + phosphate rock $+B$. subtilis), $\mathrm{C}_{8}$ (treatment of compost + sulphur $+\mathrm{AM}$ fungi), $\left(\mathrm{C}_{9}\right.$ (treatment of compost +

Egypt. J. Phytopathol., Vol. 46, No. 2 (2018) 
sulphur $+B$. subtilis) and $\mathrm{C}_{14}$ (compost + phosphate rock $+\mathrm{AM}$ fungi). However, $\mathrm{C}_{1}$ (treatment of compost), $\mathrm{C}_{11}$ (compost + gypsum $+\mathrm{AM}$ fungi treatment) and $\mathrm{C}_{2}$ (compost + AM fungi treatment) showed no significant differences among them in this respect.

The data revealed a relative increase in soil salinity (EC) as compared with control value $\left(0.80 \mathrm{dS} \mathrm{m}^{-1}\right)$ due to using all compost applications. The highest values were obtained with $\mathrm{C}_{2}$ (compost + sulphur treatment), $\mathrm{C}_{8}$ (treatment of compost + sulphur + $\mathrm{AM}$ fungi) and $\mathrm{C}_{9}$ (treatment of compost + sulphur $+B$. subtilis). The corresponding values were $0.73,0.72$ and $0.71 \mathrm{dS} \mathrm{m}^{-1}$ respectively, followed by $\mathrm{C}_{10}$ (compost + sulphur $+T$. harzianum), $\mathrm{C}_{1}$ (compost treatment), $\mathrm{C}_{7}$ (compost $+T$. harzianum), $\mathrm{C}_{5}$ (compost $+\mathrm{AM}$ fungi) and $\mathrm{C}_{6}$ (compost $+B$. subtilis) without significant differences among them while the lowest one was obtained with $\mathrm{C}_{4}$ (treatment of compost + phosphate rock) being, $0.61 \mathrm{dS} \mathrm{m}^{-1}$.

Organic carbon (OC) and organic matter (OM) contents of the soil were significantly increased with various compost treatments compared to the control treatment. The highest $\mathrm{OC}$ and $\mathrm{OM}$ contents were determined in compost + phosphate rock treatment $\left(\mathrm{C}_{4}\right)$ followed by $\mathrm{C}_{9}$ (compost + sulphur + B. subtilis), $\mathrm{C}_{15}$ (compost + phosphate rock $+\mathrm{AM}$ fungi) without significant differences among them. The corresponding mean values for OC were $1.255,1.196$ and 1.196 , respectively and for OM were 2.163, 2.063 and 2.063, respectively. While the lowest OC and OM contents were obtained due to treatment of compost only without any addition $\left(\mathrm{C}_{1}\right)$ followed by compost + B. subtilis treatment $\left(\mathrm{C}_{6}\right)$ and treatment of compost + AM fungi $\left(\mathrm{C}_{5}\right)$ without significant differences among them but are still higher than control values.

On the other hand, all the tested compost treatments significantly increased NPK content compared with control treatment. The highest value of available $\mathrm{N}$ was recorded due to using compost + phosphate rock $+B$. subtilis plots $\left(\mathrm{C}_{15}\right)$ followed by compost + phosphate rock $\left(\mathrm{C}_{4}\right)$, compost + phosphate rock + AM fungi $\left(\mathrm{C}_{14}\right)$, compost + phosphate rock $+T$. harzianum and compost + sulphur + B. subtilis $\left(\mathrm{C}_{9}\right)$ without significant differences among them. The corresponding mean values were $0.128,0.124$, $0.123,0.119$ and $0.119 \mathrm{ppm}$, respectively. While the lowest one was recorded due to application of compost only without any addition $\left(\mathrm{C}_{1}\right)$, being $0.106 \mathrm{ppm}$. Regarding phosphorus, the highest values were recorded due to treatments addition of gypsum to compost, especially that inoculated with the tested bioagents, being, $15.98 \mathrm{ppm}$ in compost + gypsum $+B$. subtilis treatment $\left(\mathrm{C}_{12}\right), 15.80 \mathrm{ppm}$ due to treatment of compost + gypsum $+T$. harzianum $\left(\mathrm{C}_{13}\right)$ and $15.75 \mathrm{ppm}$ due to treatment of compost + gypsum + AM fungi $\left(C_{11}\right)$ without significant differences among them. The lowest values were recorded with $\mathrm{C}_{1}$ (treatment of compost only), $\mathrm{T}_{8}$ (compost $+\mathrm{AM}$ fungi treatment) and $\mathrm{C}_{7}$ (compost $+T$. harzianum treatment). On the other hand, the highest values of available $\mathrm{K}$, were recorded with $\mathrm{C}_{12}$ (compost + gypsum $+B$. subtilis treatment), $\mathrm{C}_{15}$ (compost + phosphate rock + B. subtilis treatment), $\mathrm{C}_{11}$ (compost + gypsum $+\mathrm{AM}$ fungi), $\mathrm{C}_{16}$ (compost + Phosphate rock $+T$. harzianum treatment), $\mathrm{C}_{14}$ (compost + 
phosphate rock $+\mathrm{AM}$ fungi treatment), $\mathrm{C}_{9}$ (compost + sulphur + B. subtilis $), \mathrm{C}_{4}$ (compost + phosphate rock treatment), $\mathrm{C}_{13}$ (compost + gypsum $+T$. harzianum treatment), $\mathrm{C}_{13}$ (compost + gypsum treatment), $\mathrm{C}_{8}$ (compost + sulphur $+\mathrm{AM}$ fungi treatment), and $\mathrm{C}_{10}$ compost + sulphur $+T$. harzianum treatment) which lies in the same statistical group. Meanwhile the lowest values were recorded with $\mathrm{C}_{1}$ plots (treatment of compost only).

Table 9: Effect of interaction between compost amended with sulphur, phosphate, gypsum and bioagents on some physical and chemical properties of soil in the two growing seasons.

\begin{tabular}{|c|c|c|c|c|c|c|c|c|}
\hline \multirow{2}{*}{ 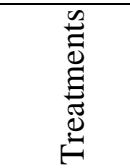 } & \multicolumn{8}{|c|}{ Mean of the two growing seasons } \\
\hline & $\mathrm{pH}$ & $\mathrm{EC}$ & OC $\%$ & OM \% & $\begin{array}{l}\mathrm{C} / \mathrm{N} \\
\text { ratio }\end{array}$ & $\begin{array}{l}\text { Total } \\
\text { N \% }\end{array}$ & $\mathrm{P}(\mathrm{ppm})$ & $\underset{(\mathrm{ppm})}{\mathrm{K}}$ \\
\hline $\mathrm{C} 1$ & 8.48 & 0.66 & 1.112 & 1.916 & 10.52 & 0.106 & 13.53 & $\begin{array}{c}252.9 \\
7\end{array}$ \\
\hline $\mathrm{C} 2$ & 8.42 & 0.73 & 1.138 & 1.961 & 10.36 & 0.111 & 14.14 & 256.63 \\
\hline $\mathrm{C} 3$ & 8.47 & 0.63 & 1.151 & 1.984 & 10.18 & 0.113 & 15.21 & 276.37 \\
\hline $\mathrm{C} 4$ & 8.43 & 0.61 & 1.255 & 2.163 & 10.12 & 0.124 & 14.33 & 280.02 \\
\hline C5 & 8.46 & 0.65 & 1.122 & 1.934 & 10.29 & 0.109 & 13.61 & 253.70 \\
\hline C6 & 8.45 & 0.65 & 1.118 & 1.928 & 10.25 & 0.109 & 14.00 & 264.67 \\
\hline $\mathrm{C} 7$ & 8.45 & 0.66 & 1.165 & 2.009 & 10.51 & 0.111 & 13.62 & 261.74 \\
\hline $\mathrm{C} 8$ & 8.38 & 0.72 & 1.131 & 1.950 & 8.66 & 0.115 & 14.62 & 276.37 \\
\hline C9 & 8.38 & 0.71 & 1.196 & 2.063 & 10.04 & 0.119 & 15.00 & 282.91 \\
\hline $\mathrm{C} 10$ & 8.37 & 0.69 & 1.138 & 1.962 & 10.18 & 0.113 & 14.61 & 273.44 \\
\hline $\mathrm{C} 11$ & 8.47 & 0.64 & 1.132 & 1.951 & 10.20 & 0.111 & 15.75 & 286.61 \\
\hline $\mathrm{C} 12$ & 8.45 & 0.62 & 1.151 & 1.984 & 10.21 & 0.113 & 15.98 & 292.45 \\
\hline $\mathrm{C} 13$ & 8.45 & 0.63 & 1.145 & 1.974 & 10.13 & 0.113 & 15.80 & 279.29 \\
\hline C14 & 8.38 & 0.63 & 1.170 & 2.017 & 9.58 & 0.123 & 15.11 & 282.95 \\
\hline $\mathrm{C} 15$ & 8.35 & 0.62 & 1.196 & 2.063 & 9.44 & 0.128 & 15.37 & 292.45 \\
\hline $\mathrm{C} 16$ & 8.37 & 0.62 & 1.160 & 2.000 & 9.84 & 0.119 & 15.24 & 285.87 \\
\hline $\mathrm{C} 17$ & 8.56 & 0.80 & 1.032 & 1.780 & 12.24 & 0.084 & 10.01 & 230.31 \\
\hline $\mathrm{C} 18$ & 8.57 & 0.80 & 1.020 & 1.754 & 12.11 & 0.087 & 9.94 & 226.65 \\
\hline $\begin{array}{c}\text { L.S.D at } \\
0.05\end{array}$ & 0.09 & 0.06 & 0.04 & 0.08 & 0.39 & 0.014 & 1.31 & 19.04 \\
\hline
\end{tabular}

Egypt. J. Phytopathol., Vol. 46, No. 2 (2018) 
Effect of compost on enzymatic activities:

Data presented in Table, 10 show the effect of the tested compost treatments on the defense related enzyme activities in the treated pepper plants compared to the untreated control. Overall, all tested treatments significantly increased the activity of defense related enzymes and phenols in pepper plants.

Combined treatments of compost with phosphate rock or gypsum inoculated with the tested bioagents resulted excess in the activity for peroxidase, polyphenoloxidase enzymes compared to the control treatment. Maximum increase in peroxidase and polyphenol oxidase activities was detected with compost + phosphate rock $+B$. subtilis treatment $\left(\mathrm{C}_{15}\right)$, being 1.893 and $0.734 \%$ respectively. The lowest activity of these enzymes was detected in pepper plants received compost only without any additions $\left(\mathrm{C}_{1}\right)$.

Table 10: Effect of compost treatments on Peroxidase and Polyphenol oxidase activities.

\begin{tabular}{|c|c|c|}
\hline \multirow{2}{*}{ Treatment } & \multicolumn{2}{|c|}{ Enzyme activity $\Delta \mathrm{A} / \mathrm{min} / \mathrm{g}$ fw } \\
\cline { 2 - 3 } & Peroxidase & Polyphenol oxidase \\
\hline C1 & 0.682 & 0.348 \\
\hline C2 & 0.785 & 0.351 \\
\hline C3 & 1.003 & 0.505 \\
\hline C4 & 1.024 & 0.371 \\
\hline C5 & 0.832 & 0.593 \\
\hline C6 & 1.072 & 0.579 \\
\hline C7 & 1.041 & 0.382 \\
\hline C8 & 0.953 & 0.396 \\
\hline C9 & 0.997 & 0.435 \\
\hline C10 & 1.009 & 0.472 \\
\hline C11 & 1.010 & 0.681 \\
\hline C12 13 & 1.253 & 0.645 \\
\hline C14 & 1.121 & 0.518 \\
\hline C15 & 1.039 & 0.734 \\
\hline C16 & 1.893 & 0.693 \\
\hline C17 & 1.312 & 0.712 \\
\hline C18 & 1.734 & 0.292 \\
\hline LSD at 0.05 & 0.413 & 0.039 \\
\hline & 0.070 & \\
\hline
\end{tabular}

\section{Dis c us sion}

Compost use is one of the most important factors which contribute in increasing productivity, soil fertility and sustainable agriculture. However, it has been known that 
compost and compost extracts alter the balance of soil microflora and can suppress foliar diseases in some crops (Stone et al., 2003 and Zaki et al., 2011). The present study demonstrated that compost extracts alone or combined with sulpher, phosphate rock or gypsum inoculated with any of the tested bioagents suppressed conidial germination of $L$. taurica in vitro assay. The suppressive activity of microbial enriched compost extracts observed in this study is likely biological in nature. Previous accumulation of soluble nutrients from compost to compost extract during brewing time enhanced beneficial microorganisms in extract (Ingham, 2005), which produce antimicrobial compounds. Also the present study demonstrated that addition of phosphate rock and gypsum to compost and inoculated with bioagents (B. subtilis, $T$. harzianum and AM fungi) significantly caused different degrees of reduction of pepper powdery mildew incidence and severity compared to the control under field conditions. Addition of phosphate rock to compost and inoculated with B. subtilis showed the highest efficacy in this concern. This result is in line with the reports of Segarra et al. (2009a, b). Brinton et al. (1996) reported that the principal active agents in compost extract appear to be the genera Bacillus and Trichoderma which caused inhibition of spore germination, antagonism and competition with pathogens and induced resistance against pathogens when sprayed onto plant leaves act in the phyllosphere (i.e. the leaf surface). Mechanisms of action underlying the efficacy of compost and compost extracts to control plant pathogens have been reported as single or multiple mechanisms involving microbial antagonism (through antibiosis, parasitism, competition for nutrients/space or induced plant resistance) (Zhang et al., 1998; Litterick et al., 2004 and Al Mughrabi et al., 2008) or suppressive physicochemical properties (improved nutrient status of the plant, toxic compounds or induced resistance) (Hoitink et al., 1997). Calcium plays an important role in the defense of plants against pathogens, since it is essential in the structure of the middle lamellae of plant cells and in maintaining selectivity of cell plasma lemmas (Paula Júnior et al., 2009). However, disease reduction was accompanied with a gradual increase in peroxidase and polyphenoloxidase activity contents. In the present study, soil amendment with the tested compost treatments and spraying the foliage with their compost extracts significantly strongly induced synthesis and accumulation of peroxidase, polyphenoloxidase that sprayed only by compost extracts. This result is in agreement with reports of (Nwogbaga \& Iwuagwu (2015) and Siddiqui et al. (2009) who reported that compost extracts increase peroxidase, polyphenoloxidase, phenylalanine ammonia lyase, $\beta-1,3$-glucanase and chitinase in okra, tomato and onion plants when applied to foliage. The induction of plant resistance by compost extract could be attributed to the presence of beneficial microorganisms which are responsible for induction of systemic resistance (Segarra et al., 2009b). Also, the compost was rich in inorganic salts, organic carbon and phenols, which can affect pathogen growth and phyllosphere microorganisms (Segarra et al., 2009a). 
Our results showed a general increase in both plant growth characteristics (plant height, number of branches / plant, fruit yield / plant, fruit fresh due to due to using tested compost treatments as soil amendments and compost extracts as foliar spray either alone or amended with sulphur, phosphate rock or gypsum inoculated with the tested bioagents compared with control plants. The enhancement effect of compost may be resulted from a greater concentration of plant nutrients like $\mathrm{N}, \mathrm{P}, \mathrm{K}$, and $\mathrm{Mg}$ and a root reinforcement induced by compost (Donn et al., 2014 and Nadjet et al., 2014).

Sulphur gave the lowest effect in this regard either when applied alone or mixed with the tested bioagents to compost treatments. This result is in agreement with the report of Magarey et al. (2002) who reported that sulphur is toxic to most fungi including many of the antagonistic to Uncenula necator. Also Sulphur is a multi site fungicide which inhibits the production or activity of the range of enzymes.

Compost amended with phosphate rock and inoculated with bioagents recorded the. highest effect compared to the other treatments. Addition of phosphate supplementing microorganisms as B. subtilis, T. harzianum and AM fungi influenced phosphate rock solubility and stimulated pepper roots to absorb more $\mathrm{P}$ from the soil and its transporting towards shoots, resulting in stimulating the overall plant growth as compared to each treatment alone. Phosphorus is a responsible element about structural of the membrane system of the cell, the mitochondria and chloroplast (Akande et al., 2008a).The methods of promoting the quality of phosphate rock and its agronomic efficiency include composting with organic manures (Adediran \& Sobulo, 1997).Combination of poultry manure or cow dung with phosphate rock significantly improved release of $\mathrm{P}$ and performance of crops (Akande et al., 2005 and Akande et al., 2008b).The microbial activities stimulated nutrients uptake and plant growth may be due to hormones such as auxin or gibberellic acid production as declared by ContrerasCornejo et al. (2016). The arbuscular mycorrhizal fungi (AMF) compose a symbiotic relationship with the roots of most plants by increasing plant phosphate (P) uptake and growth, while plants provide the AM fungi with exudates for metabolism (Smith et al., 2003). Gypsum is a moderately soluble source of the essential plant nutrients, calcium and sulphur, and can improve overall plant growth. Our results showed that application of different treatments of compost tested to soil cultivated with pepper plant increased soil salinity (EC), organic carbon (OC), organic matter (OM), available nitrogen, phosphorous and potassium (NPK) contents and decreased $\mathrm{pH}$. The reduction in $\mathrm{pH}$ value is in agreement with Moreno et al. (1997) who mentioned that the reduction in $\mathrm{pH}$ results at the end of the growing season due to the root exudates, the release of NH4+ and the nitrification process which takes place during the course of plant growing period. $\mathrm{CO}_{2}$ released into soil atmosphere due to decomposition of organic wastes can be converted into carbonic acid $\left(\mathrm{H}_{2} \mathrm{CO} 3\right)$ by reacting with water $(\mathrm{H} 2 \mathrm{O})$ and decreases soil pH (Chang et al., 1991 and Sağlam, 1997). Dahdoh and Hassan (1997) showed the same results where application of compost increased the EC results and attributed that to the releasing substances from compost treatment which may directly or indirectly 
raised soil EC due to the microbial decomposition. The increased NPK contents in the soil are in agreement with Abou El-Naga et al. (1996), who pronounced that increasing organic manure addition increased nutrient availability in the soil due to moreover amounts of available nutrients released from the decomposed organic manure. Rodriguez-Vila et al. (2016) confirmed that organic amendments sustain soil properties by rising organic matter, nutrient content, and microbial activity and thus increase crop growth and yield.

Therefore, this study can support the usefulness of inoculation of compost with any of the tested bioagents and soil amendment with compost on spraying the pepper plants with compost extract to control powdery mildew and improve production of pepper plants as well as improve soil fertility.

\section{References}

A.O.A.C. 1975. Official methods of analysis of association of agricultural chemists. Washington, DC. $10^{\text {th }}$ ed.

Abou El-Naga, S.A.; Omran, M.S. and Shehata, A.M. 1996. The combined effect of organic manure (FYM) and irrigation regime on the biological activity and nutrients availability in green pepper. J. Soil Sci., 36(1-4): 33-45.

Adediran, J.A. and Sobulo, R.A. 1997. The potentials and use of rock phosphates in the Sub Saharan Africa. A case study in Nigeria. In: (Agboola et al.) Proceedings of $3^{\text {rd }}$ All African Soil Society, University of Ibadan, Ibadan. Nigeria, August 1995. pp 295-305.

Agrios, N.G. 2005. Plant Pathology 5th Edition, Elsevier Amsterdam, 635.

Akande, M.O.; Adediran, J.A. and Oluwatoyinbo, F.I. 2005. Effect of rock phosphate amended with poultry manure on soil available $\mathrm{P}$ and yield of maize and cowpea. African J. Biotechnol., 4: 444-448.

Akande, M.O.; Adediran, J.A.; Oluwatoyinbo, F.I.; Makinde, E.A. and Adetunji, M.T. 2008a. Suitability of poultry manure amended rock phosphate on growth, nutrient uptake and yield of Chilli pepper (Capsicum fruitscens L). Nigerian J. Soil Sci., 18: 178-186.

Akande, M.O.; Oluwatoyinbo, F.I.; Kayode, C.O. and Olowookere, F.A. 2008b. Effects of Ogun phosphate rock amended with different levels of cow dung on the growth and yield of maize okra intercrop relayed with cowpea. African J. Biotechnol., 7(17): 3039-3043.

Al-Mughrabi, K.I.; Bertheleme, C.; Livingston, T.; Burgoyne, A.; Poirier, R. and Vikram, A. 2008. Aerobic compost extract, compost and a combination of both reduce the severity of common scab (Streptomyces scabiei) on potato tubers. J. Plant Sci., 3(2): 168-175. 
Brinton, W.F.; Tränkner, A. and Droffner, M. 1996. Investigations into liquid compost extracts. Biocycle, 37(11): 68-70.

Bourbos, V.A.; Skoudridakis, M.T. and Barbopoulou, E., 1999. Sodium bicarbonate for the control of Erysiphe polygoni in greenhouse tomato. Acta Horticulturae 487: 275-278.

Chang, C.; Sommerfeldt, T.G. and Entz, T. 1991. Soil chemistry after eleven annual applications of cattle feedlot manure. J. Environ. Qual., 20: 475-480.

Cohen, Y.; Gisi, U. and Mosinger, E.1991. Systemic resistance of potato plants against Phytophthora infestans induced by unsaturated fatty acids. Physiol. Mol. Plant Pathol., 38: 255-263.

Contreras-Cornejo, H.A.; Macías-Rodríguez, L.; del-Val, E. and Larsen, J. 2016. Ecological functions of Trichoderma spp. and their secondary metabolites in the rhizosphere: interactions with plants. FEMS Microbiology Ecology, 92(4): 1-17.

Csillery, G. 2006. Pepper taxonomy and the botanical description of the species. Acta Agronomica Hungarica, 54(2), 151-166

Dahdoh, M.S.A. and Hassan, F.A. 1997. Combined effect of sewage sludge and saline water irrigation on growth and elements composition of broad bean. Egypt. J. Soil Sci., 37(2):189-204.

Donn, S.; Wheatley, R.E.; McKenzie, B.M.; Loades, K.W. and Hallett, P.D. 2014. Improved soil fertility from compost amendment increases root growth and reinforcement of surface soil on slope. Ecological Engineering, 71:458-465.

Dutta, S.; Ghosh, P.P.; Ghorai, A.K.; De Roy, M. and Das, S. 2017. Micronutrients and plant disease suppression. Fertilizers and Environment News, 3(2): 2-6.

Elad Y.; Chet, I. and Henis, Y. 1981. A selective medium for improving quantitative isolation of Trichoderma spp. from soil. Phytoparasitica, 9: 59-67.

Esterbaner, H.; Schwarzl, E. and Hayn, M. 1977. A rapid assay for catechol oxidase and laccase using 2-nitro-5-thio benzoic acid. Anal. Biochem., 77:486-494.

García-López, A.M. and Delgado, A. 2016. Effect of Bacillus subtilis on phosphorus uptake by cucumber as affected by iron oxides and the solubility of the phosphorus source. Agric. \& Food Sci., 25: 216-224.

Gharib, F.A.; Moussa L.A. and Massoud, O. 2008. Effect of compost and bio-fertilizers on growth, yield and essential oil of sweet Marjoram (Majorana hortensis) plant. Int. J. Agric. Biol., 10: 381-387.

Hoitink, H.A.; Stone, A.G. and Han, D.Y. 1997. Suppression of plant diseases by composts. Hortscience, 32: 184-187. 
Ingham, E.R. 2005. In: "The Compost Tea Brewing Manual". 5th Ed., Soil Foodweb Inc., Corvallis, Oregon.

Khan, M.S.; Zaidi, A.; Ahemad, M.; Oves, M. and Wani, P.A. 2010. Plant growth promotion by phosphate solubilizing fungi-current perspective. Arch. Agron. Soil Sci., 56:73-98.

Kim, Y.S.; Song, J.G.; Lee, I.K.; Yeo, W.H. and Yun, B.S. 2013. Bacillus sp. BS061 suppresses powdery mildew and gray mold. Mycobiology, 41(2): 108-111.

Litterick, A.M.; Harrier, L.; Wallace, P.; Watson, C.A. and Wood, M. 2004. The role of uncomposted materials, composts, manures, and compost extracts in reducing pest and disease incidence and severity in sustainable temperate agricultural and horticultural crop production-a review. Critical Reviews in Plant Sciences, 23: 45379.

Magarey, P. A.; Emmett, R.W.; Wicks, T. J. and Hitch, C. 2002. The phytotoxicity of sulphur applied to grapevines at high temperature. In "Proceedings of the Fourth International Workshop on Powdery and Downy Mildew in Grapevines". D.M. Gadoury, C. Gessler, G. Grove, W.D. Gubler, G.K. Hill, H-H. Kassemeyer, W.K. Kast, J. Rumbolz and E.S. Scott (Eds.), Department of Plant Pathology, University of California, Davis, CA. p. 82-83.

Matsuda, Y.; Kasshimoto, K.; Takikawa, Y.; Aikami, R.; Nonomura, T. and Toyoda H., 2001. Occurrence of new powdery mildew on greenhouse tomato cultivars. Journal of General Plant Pathology, 67: 294-298.

Moreno, J.L.; Garcia, C.; Hernandez, T. and Ayuso, M. 1997. Application of composted sewage sludge contaminated with heavy metals to an agricultural soil: Effect on lettuce growth. Soil Sci. Plant Nutr., 43(3): 565-73.

Nadjet, M.; Abderezzak, D. and Meriem, K.H. 2014. Effect of three types of composts of olive oil by-products on growth and yield of hard wheat "Triticum durum Desf.". Afr. J. Biotechnol., 13(52):4685-4693.

Nwogbaga, A.C. and Iwuagwu, C.C. 2015. Effect of fungicide and N.P.K foliar fertilizer application for the management of fungal diseases of cucumber (Cucumis sativus L.). Scholars Journal of Agriculture and Veterinary Sciences, 2(3A):182186.

Paula Júnior, T.J.; Vieira, R.F.; Teixeira, H. and Carneiro, J.E.S. 2009. Foliar application of calcium chloride and calcium silicate decreases white mold intensity on dry beans. Trop. Plant Pathol., 34(3): 171-174.

Rajput, J.C. and Y. R.Poruleker, 1998. Capsicum in Handbook of vegetable science and technology (D.K. Salunkhe and S.S. Kadam, eds.) Marcel Dekker, Inc. New York, p.721- 729 .

Egypt. J. Phytopathol., Vol. 46, No. 2 (2018) 
Reuveni, R. and Reuveni, M. 1998. Foliar-fertilizer therapy-a concept in integrated pest management. Crop Prot., 17: 111-118.

Rivero, C.; Chirenje, T.; Ma, L.Q. and Martinez, G. 2004. Influence of compost on soil organic matter quality under tropical conditions. Geoderma., 123: 355-361.

Rodriguez-Vila, A.; Asensio, V.; Forjan, R. and Covelo, E.F. 2016. Carbon fractionation in a mine soil amended with compost and biochar and vegetated with Brassica juncea L. J. Geochemical Exploration, 169: 137-143.

Ryckeboer, J.; Mergaert, J.; Vaes, K.; Klammer, S.; De Clercq, D.; Coosemans, J.; Insam, H. and Swings, J. 2003. A survey of bacteria and fungi occurring during composting and self heating processes. Ann. Microbiol., 53: 349-410.

Sağlam, M. T. 1997. Toprak Kimyası. Trakya Üniv. Zir. Fak. Yay.190. Ders Kitabi No: 21. (in Turkish).

Segarra, G.; Reis, M.; Casanova, E. and Trillas, M.I. 2009a. Control of powdery mildew (Erysiphe polygoni) in tomato by foliar applications of compost tea. J. Plant Pathol., 91 (3): 683-689.

Segarra, G.; Van der Ent, S.; Trillas, I. and Pieterse, C.M.J. 2009b. MYB72, a node of convergence in induced systemic resistance triggered by a fungal and a bacterial beneficial microbe. Plant Biology, 11: 90-96.

Siddiqui, Y.; Sariah, M.; Razi, I. and Mawardi, R. 2009. Bio-potential of compost tea from agro-waste to suppress Choanephora cucurbitarum L. the causal pathogen of wet rot of okra. Biological Control, 49:38-44.

Smith, S.E.; Smith, F.A. and Jakobsen, I. 2003. Mycorrhizal fungi can dominate phosphate supply to plants irrespective of growth responses. Plant Physiol., 133: 16-20.

Snedecor, G.W. and Cochran, W.G. 1989. "Statistical Methods". 8th. ed. Iowa State Univ. Press, Ames, Iowa, USA, 251 pp.

Stone A.; Vallad, G.; Cooperband, L.; Rotenberg. D.; Darby, H.; James, R.; Stevenson, W. and Goodman, R., 2003. Effect of organic amendments on soil borne and foliar diseases in field-grown snap bean and cucumber. Plant Dis. 87(9):1037-1042

Tallapragada, P. and Gudimi, M. 2011. Phosphate solubility and biocontrol activity of Trichoderma harzianum. Turk J. Biol., 35: 593-600.

Tanwar, A.; Aggarwal, A.; Kadian, N. and Gupta, A. 2013. Arbuscular mycorrhizal inoculation and super phosphate application influence plant growth and yield of Capsicum annuum. J. Soil Sci. \& Plant Nut., 13(1): 55-66. 
Vallad GE.; Cooperband, L. and Goodman, RM., (2003) Plant foliar disease suppression mediated by composted forms of paper mill residuals exhibits molecular features of induced resistance. Physiol Mol Plant Pathol., 63(2):65-77

Worthington, x. x. 1971. "Enzyme Manual", Worthington Biochemical Corp., Freehold, New Jersey. 41-45.

Zaccardelli, M., C. Pane, R. Scotti, A. M. Palese and G. Celano, 2012. Use of composttea as bio-agrochemicals and bio-stimulants in horticulture. Italus Hortus., 19: 1728.

Zaki, K.I.; Zayed, Mona S. and Abd-Alraheim, A.M. 2011. Foliar application of compost-tea and bicarbonate salts for controlling powdery mildew disease on squash plants in North Sinai. Egypt. J. Phytopathol., 39(1): 201-220.

Zhang, W.; Dick, W.A. and Hoitink, H.A.J. 1996. Compost-induced systemic acquired resistance in cucumber to Pythium root rot and anthracnose. Phytopathology, 86: 1066-1070.

Zhang, W.; Han, D.Y.; Dick, W.A.; Davis, K.R. and Hoitink, H.A.J. 1998. Compost and compost water extract-induced systemic acquired resistance in cucumber and Arabidopsis. Phytopathology, 88: 450-455.

Zhang, L.; Zhou, J.; Zhao, Y. G.; Zhai, Y.; Wang, K.; Alva A. K. and Paramasivam, S. 2013. Optimal Combination of Chemical Compound Fertilizer and Humic Acid to Improve Soil and Leaf Properties, Yield and Quality of Apple (Malus domestica). Pakistan Journal of Botany, 45: 1315-1320.

(Received 23/09/2018;

in revised form 29/10/2018) 
APPLICSTION OF COMPOST FOR CONTROLLING POWDERY MILDEW... 155

$$
\begin{aligned}
& \text { إستخدام الكمبوست في مكافحة البياض الدقيقي على الإنى } \\
& \text { القلقل و تأثيره على الإنتاجية }
\end{aligned}
$$

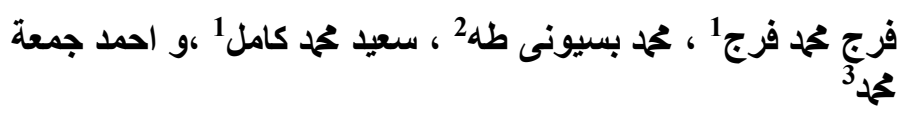

$$
\begin{aligned}
& \text { 1- معهد بحوث أمراض النباتات ، مركز البحوث الزراعية ، الجيزة ، } \\
& \text { مصر } \\
& \text { 2- معهد بحوث الاراضى والمياة والبيئة ،مركز البحوث الزراعية ، }
\end{aligned}
$$

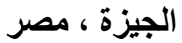

$$
\begin{aligned}
& \text { 3- معهد بحوث البساتين ، مركز البحوث الزراعية ، الجيزة ، مصر }
\end{aligned}
$$

تم تقييم كفاءة الكمبوست (حطب الذرة المعامل بسماد الغنم) مع الكبريت

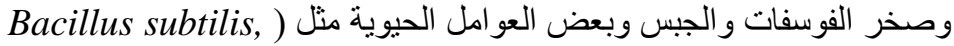

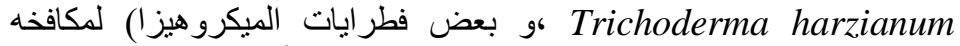

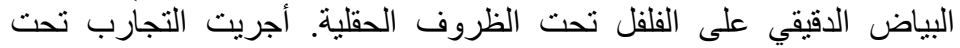
ظروف العدوى الطبيعية في المزرعة التجريبية لمحطة بحوث البئه البساتين في

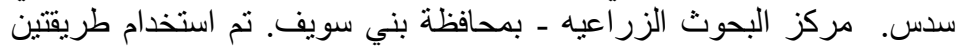

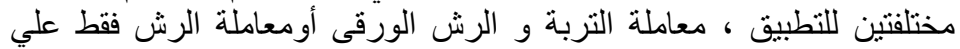

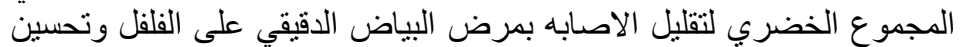

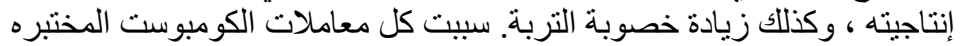

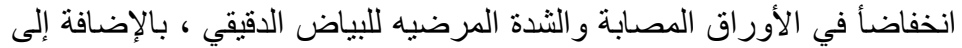

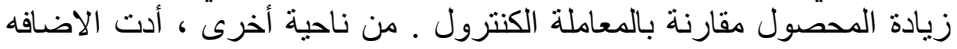

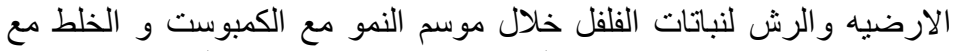
Trichoderma harzianum

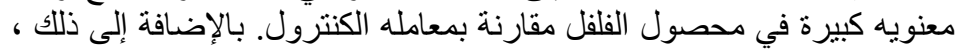

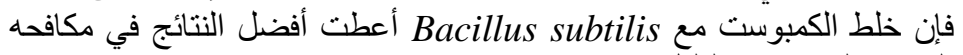

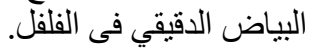

